\title{
Oxytocin-Induced Postinhibitory Rebound Firing Facilitates Bursting Activity in Oxytocin Neurons
}

\author{
Jean-Marc Israel ${ }^{1,2}$ Dominique A. Poulain, ${ }^{1,2}$ and Stéphane H. R. Oliet ${ }^{1,2}$ \\ ${ }^{1}$ Neuroscience Research Center, Inserm U862, Bordeaux, France; ${ }^{2}$ Université Victor Segalen Bordeaux 2, Bordeaux, France
}

\begin{abstract}
During parturition and lactation, neurosecretory oxytocin (OT) neurons in the hypothalamus achieve pulsatile hormone secretion by coordinated bursts of firing that occur throughout the neuronal population. This activity is partly controlled by somatodendritic release of OT, which facilitates the onset and recurrence of synchronized bursting. To further investigate the cellular mechanisms underlying the control exerted by $\mathrm{OT}$ on the activity of its own neurons, we studied the effects of the peptide on membrane potential and synaptic activity in OT neurons in hypothalamic organotypic slice cultures. Bath application of low concentrations of OT $(<100 \mathrm{nM})$ facilitated $\mathrm{GABA}_{\mathrm{A}}$ receptor-mediated inhibitory transmission through a presynaptic mechanism without affecting membrane potential and excitatory glutamatergic synaptic activity. The facilitatory action of OT on GABAergic transmission was dose-dependent, starting at $25 \mathrm{~nm}$ and disappearing at concentrations $>100 \mathrm{~nm}$. As shown previously, higher concentrations of OT ( $>500 \mathrm{~nm}$ ) had the opposite effect, inhibiting $\mathrm{GABA}_{\mathrm{A}}$ receptors via a postsynaptic mechanism. Surprisingly, OT-mediated facilitation of GABAergic transmission promoted action potential firing in $40 \%$ of the neurons. Each action potential occurred at the end of the repolarizing phase of an inhibitory potential. Pharmacological dissection revealed that this firing involved the activation of low-threshold activated calcium channels. Detailed statistical analysis showed that OT-mediated firing upregulated bursting activity in OT neurons. It is thus likely to optimize OT secretion and, as a consequence, facilitate delivery and milk ejection in mammals.
\end{abstract}

Key words: hypothalamus; supraoptic; GABA; calcium current; neuroendocrine; lactation

\section{Introduction}

Oxytocin (OT) is a hormone synthesized in magnocellular neurons that are located in the paraventricular (PVN) and supraoptic (SON) nuclei of the hypothalamus. During parturition and lactation in the rat, OT neurons display periodic high frequency bursts of action potentials (AP) that are synchronized in the whole OT neuron population. This triggers a massive and pulsatile release of OT in the blood stream which, in turn, promotes pup delivery and milk ejection (Poulain and Wakerley, 1982; Wakerley et al., 1988). OT is also released from the somatodendritic compartment, a process that enables OT neurons to regulate their own activity (Richard et al., 1991). Locally released OT is essential to the onset of the milk ejection reflex (Moos et al., 1989; Neumann et al., 1993) and it enhances the amplitude and frequency of suckling-induced bursts, an effect mimicked by injections of OT in the third ventricle (Freund-Mercier and Richard, 1984). Conversely, injection of an OT receptor (OT-R) antagonist directly in the SON or PVN greatly reduces bursting activity (Lambert et al., 1993). Furthermore, OT appears to have the property of priming and inducing its own release, thereby

Received July 25, 2005; accepted Nov. 26, 2007.

This work was supported by grants from INSERM and the Conseil Régional d'Aquitaine (20030301211N). We thank Dr. D. T. Theodosis and Prof. D. Voisin for critical reading of this manuscript and N. Dupuy for technical assistance with the cultures.

Correspondence should be addressed to Jean-Marc Israel, Inserm U862, 146 rue Léo-Saignat, 33077 Bordeaux, France. E-mail:jean-marc.israel@bordeaux.inserm.fr.

DOI:10.1523/JNEUROSCI.5198-07.2008

Copyright $\odot 2008$ Society for Neuroscience $\quad$ 0270-6474/08/280385-10\$15.00/0 amplifying its local and long distance action (Moos et al., 1984; Ludwig and Leng, 2006).

In vitro recordings have revealed that the periodic high frequency bursting of OT neurons was driven by OT-sensitive glutamatergic inputs (Jourdain et al., 1998; Israel et al., 2003). In addition, OT at fairly high concentrations $(1-10 \mu \mathrm{M})$ is known to inhibit glutamate (Kombian et al., 1997) and GABA release (De Kock et al., 2003) through presynaptic mechanisms as well as $\mathrm{GABA}_{\mathrm{A}}$ receptor-mediated responses via a postsynaptic process (Brussaard et al., 1996). How these different effects come into play to modulate OT neuron excitability, especially during lactation, remains unknown. To address this issue we investigated the effects of OT applied at very low to large concentration (25-2000 nM) on identified OT neurons in vitro (Jourdain et al., 1996). A low concentration of OT $(<100 \mathrm{~nm})$ did not affect membrane potential and excitatory postsynaptic activity but triggered or accelerated $\mathrm{GABA}_{\mathrm{A}}$ receptor mediated synaptic responses, through a presynaptic action. In $\sim 40 \%$ of OT neurons, the enhancement of inhibitory transmission had the unexpected consequence of facilitating AP firing through a postinhibitory rebound (PIR) after individual IPSPs and involving the activation of a low-voltage-activated (LVA) calcium current, as revealed by pharmacological analysis. We found that OT-mediated PIR firing was responsible for the increase in firing rate observed in OT neurons before burst occurrence, an increase tightly correlated to burst amplitude, thus providing a further mechanism for optimizing hormone output during pup delivery and lactation in mammals. 


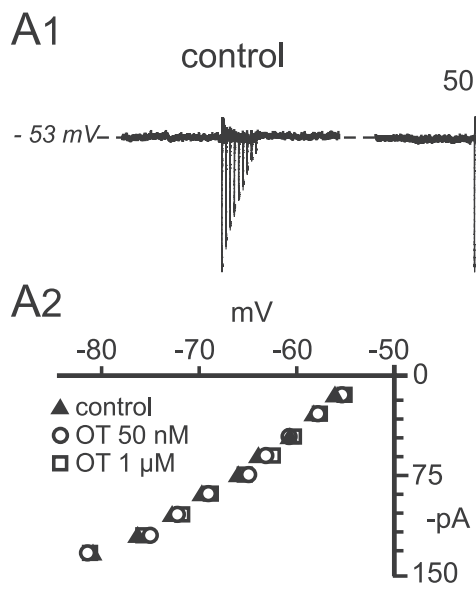

B
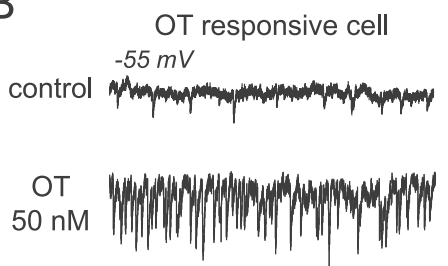

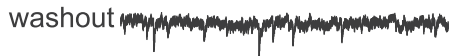
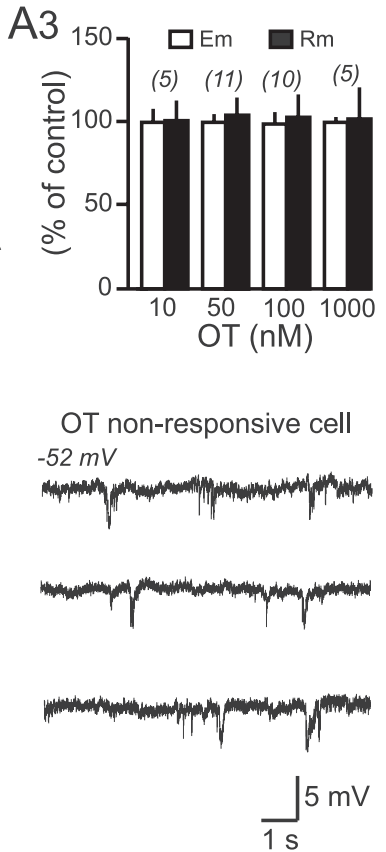

Figure 1. OT facilitates inhibitory transmission. A1, Example of a recording where $0 T$ was applied at two different concentrations ( $50 \mathrm{~nm}$ and $1 \mu \mathrm{M}$ ) in the presence of TTX, bicuculline, CNQX, and AP5. The peptide did not affect membrane potential nor membrane resistance measured from negative current pulses of decreasing amplitude (from -150 to $0 \mathrm{pA}$ by successive $15 \mathrm{pA}$ steps). $\boldsymbol{A 2}$, Voltage-current relationship obtained from the experiment shown in $\boldsymbol{A 1}$. The presence of $0 \mathrm{~T}$ did not modify this relationship. $\mathbf{A 3}$, Histogram summarizing the lack of action of $\mathrm{OT}(10 \mathrm{~nm}$ to $1 \mu \mathrm{M})$ on membrane potential (Em) and membrane resistance $(\mathrm{Rm})$ in OT-sensitive cells. The numbers of experiments are indicated in brackets. $\boldsymbol{B}$, In the presence of CNQX, application of $50 \mathrm{~nm}$ OT reversibly increased IPSP activity in 72\% of OT neurons as illustrated in the example on the left ( $0 \mathrm{~T}$ responsive cell). In the remaining neurons (28\%), GABAergic synaptic transmission was unaffected as shown on the example illustrated on the right (OT-nonresponsive cell).

\section{Materials and Methods}

Slice preparation. Cultured slices were prepared using the roller tube method as described previously (Jourdain et al., 1996). Briefly, 4- to 6-d-old female Wistar rats were anesthetized with isoflurane $\left(95 \% \mathrm{O}_{2}\right.$ and $5 \%$ isoflurane) for $1 \mathrm{~min}$ and decapitated. Brains were removed, and tissue blocks that included the hypothalamus were quickly dissected and sectioned $(400 \mu \mathrm{m})$. Frontal slices containing the supraoptic nucleus (SON) were cut into two parts along the third ventricle, and each part was placed on a glass coverslip coated with heparinized chicken plasma. Thrombin was then added to the coverslip to coagulate the plasma and permit adhesion of the slice to the coverslip. The coverslip was inserted into a plastic flat-bottomed tube (Nunc, Roskilde, Denmark) containing $750 \mu \mathrm{l}$ of medium ( $\mathrm{pH} 7.4 ; 295 \mathrm{mOsm} / \mathrm{kg}$ ), composed of 50\% Eagle's basal medium (Invitrogen, Gaithersburg, MD), 25\% heat-inactivated horse serum (Invitrogen), and 25\% HBSS (Invitrogen) enriched with glucose $(7.5 \mathrm{mg} / \mathrm{ml})$ and $2 \mathrm{~mm}$ L-glutamate (Seromed, Berlin, Germany). No antibiotics were used. The tubes were tightly capped and inserted in a roller drum; the tubes were rotated $\sim 15$ turns/h. The medium was replaced twice a week.

Recordings were performed in 2- to 10 -week-old cultures using a temperature-controlled chamber $\left(36.0 \pm 0.2^{\circ} \mathrm{C}\right)$ perifused with a solution containing (in mM) $125 \mathrm{NaCl}, 3 \mathrm{KCl}, 1 \mathrm{MgSO}_{4}, 1.25 \mathrm{KH}_{2} \mathrm{PO}_{4}, 5$

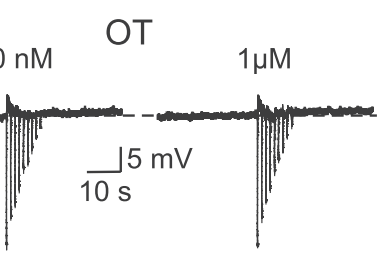

A

control
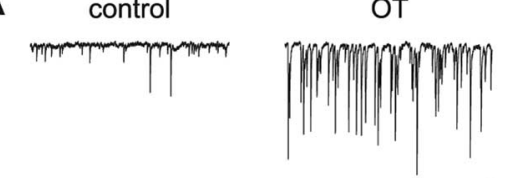

washout

B
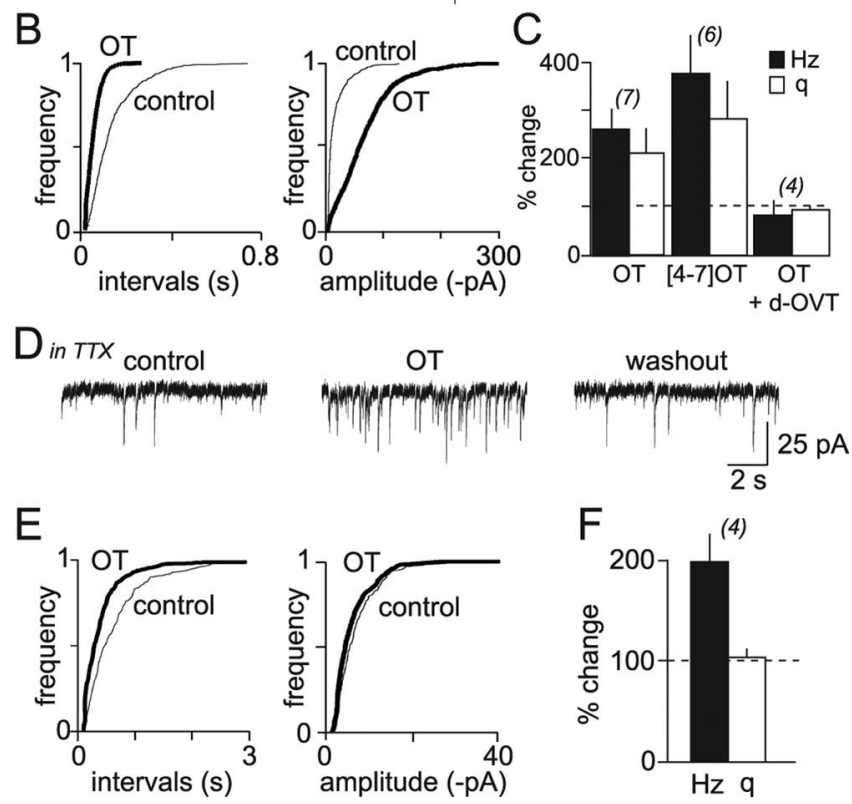

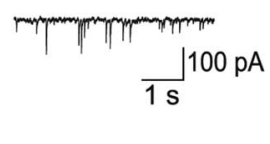

Figure 2. OT acts at presynaptic sites. $\boldsymbol{A}$, IPSC activity was increased in a reversible manner by $50 \mathrm{~nm}$ OT. $\boldsymbol{B}$, Cumulative distributions of IPSC intervals (left) and amplitude (right) indicated that $0 \mathrm{~T}$ increased both the frequency and the amplitude of these events. $\boldsymbol{C}$, Histogram summarizing the action of OT, the agonist [4-7] OT and OT plus the antagonist D-OVT on IPSP frequency $(\mathrm{Hz})$ and amplitude (q). The number of cells is indicated in brackets. $\boldsymbol{D}$, The activity of miniature IPSCs recorded in the presence of TTX was also reversibly increased by 0T ( $50 \mathrm{~nm}$ ). $\boldsymbol{E}$, Cumulative distributions for miniature IPSC intervals and amplitude indicated that $0 T$ increased the frequency without affecting the amplitude of these unitary events. $\boldsymbol{F}$, Summary histograms illustrating the effect of OT on the frequency and amplitude of miniature IPSCS $(n=4)$.

$\mathrm{NaHCO}_{3}, 2 \mathrm{CaCl}_{2}, 5$ glucose, and 10 HEPES, pH 7.25, 290-295 mOsm/ $\mathrm{kg}$. Intracellular microelectrodes were filled with $1 \mathrm{M}$ potassium acetate and $1 \%$ biocytin (Sigma, St. Louis, MO). Electrode resistance varied from 150 to $250 \mathrm{M} \Omega$. The patch clamp technique was used in whole cell configuration (current or voltage clamp mode) using electrodes (4-8 M $\Omega$ ) filled with a solution containing (in $\mathrm{mM}$ ) $120 \mathrm{~K}$-gluconate, $20 \mathrm{KCl}, 10$ HEPES, 1 EGTA, $1.3 \mathrm{MgCl}_{2}, 0.1 \mathrm{CaCl}_{2}, 2 \mathrm{Mg}$-ATP, and $0.3 \mathrm{GTP}$. For IPSC recording, electrodes were filled with (in mM) $141 \mathrm{CsCl}, 10 \mathrm{HEPES}$, 5 QX-314-Cl, and $2 \mathrm{Mg}$-ATP. Series resistance (10-25 M $\Omega$ ) was monitored on line and cells were excluded if $>20 \%$ change occurred during the experiment.

Signals were filtered at $2 \mathrm{kHz}$, digitized at $5 \mathrm{kHz}$ and analyzed using pClamp 9 (Molecular Devices, Union City, CA). Firing rate preceding high-frequency burst was estimated from frequency histograms calculated over $0.5 \mathrm{~s}$ integration periods and plotted versus time using pClamp9. The preburst period was defined as the period occurring $20 \mathrm{~s}$ before burst incidence. A change in basal firing frequency was considered as significantly different when changes exceeded $10 \%$ of control values measured during the $200 \mathrm{~s}$ period preceding the preburst period (Gouzènes et al., 1998). Detection of synaptic events was achieved offline using a sliding template whereas action potentials were detected using an amplitude threshold (AxoGraph Scientific, Kagi, Berkeley, CA). An action potential was considered triggered by an IPSP if occurring within $300 \mathrm{~ms}$ of IPSP onset. Values are expressed as means \pm SD. Data obtained were compared statistically with the nonparametric Kolmogorov-Smirnov test or the paired Student's test.

Drugs. The following were added to the bath medium when required: synthetic OT (Peninsula, Lakewood, CA), the OT-R agonist 


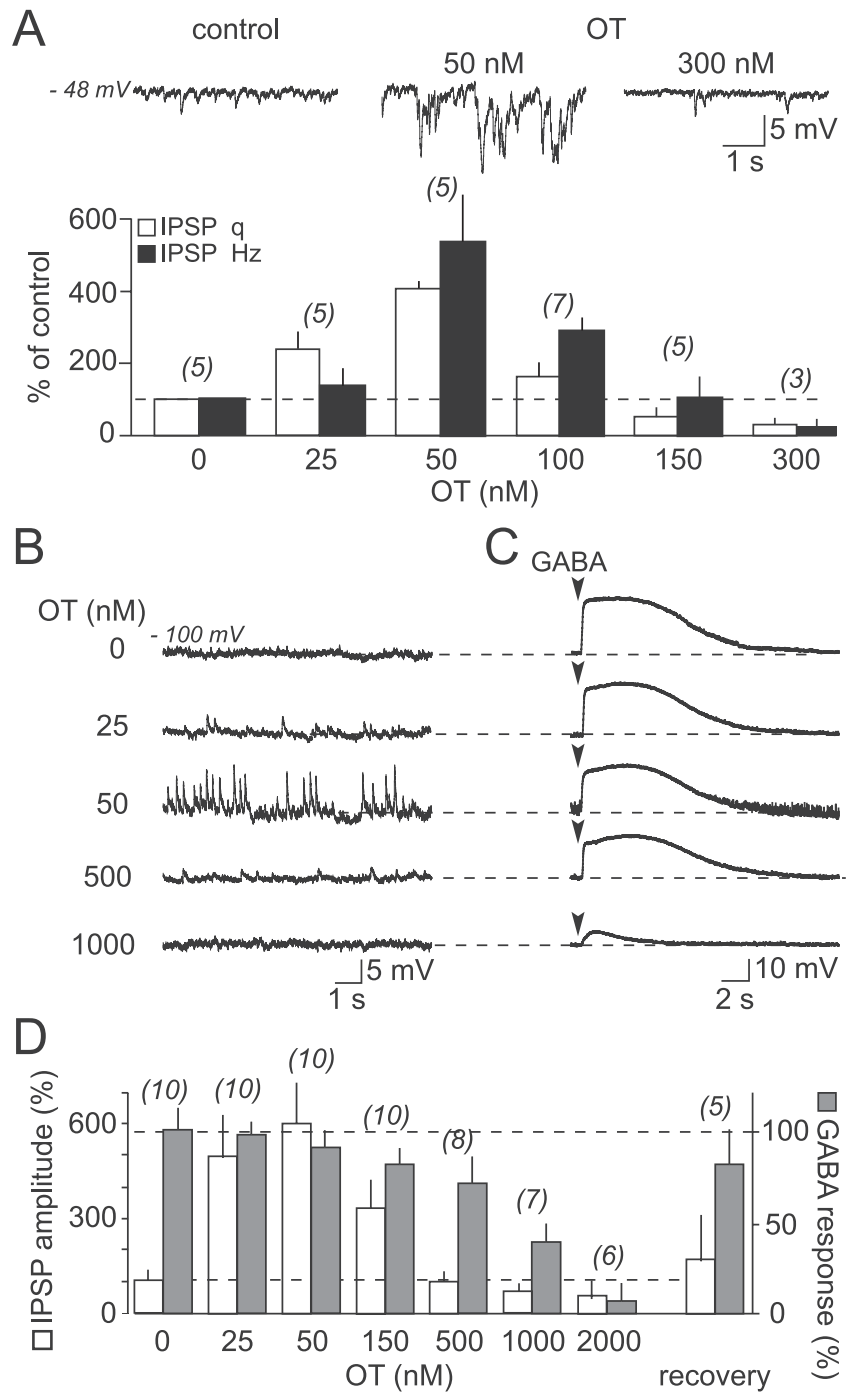

Figure 3. OT has bimodal effects on GABAergic transmission. $\boldsymbol{A}$, Histograms summarizing the changes in IPSP amplitude and frequency induced by different concentrations of OT. Insets are example obtained from a cell where OT was successively applied at 50 and $300 \mathrm{~nm}$. OT triggered or facilitated IPSP activity at a threshold concentration of $25 \mathrm{~nm}$, an effect attenuated at higher concentrations ( $>100 \mathrm{~nm}$ ). Maximal facilitation for both IPSP amplitude and frequency was obtained at 50-100 nм 0T. B, C, Example of an 0T neuron where 0T, from 25 to $1000 \mathrm{~nm}$, had distinct effects on IPSPs $(\boldsymbol{B})$ and on responses induced by local puffs of GABA ( $\boldsymbol{C}$. At $25 \mathrm{~nm}$, OT slightly increased synaptic activity without modifying the amplitude of the postsynaptic response. With 50 nм OT, IPSP activity was dramatically augmented whereas GABAinduced postsynaptic response was unaffected. At $500 \mathrm{~nm}$, IPSP activity was strongly reduced whereas the postsynaptic response was only slightly inhibited. Finally, $1000 \mathrm{~nm}$ OT inhibited totally IPSPs and almost completely the postsynaptic response. D, Summary histogram illustrating the action of OT at different concentrations on the amplitude of both IPSPs (open bars) and GABA-induced responses (gray bars) obtained from the same neurons. Numbers of experiments are indicated in brackets.

[4-threonine, 7-glycine]-oxytocin ([Thr4, Gly7]-OT ([4-7] OT), the OT-R antagonist desGly-NH2d(CH2)5[-DTyr2,Thr4]OVT (D-OVT; gifts from Dr. Manning, University of Toledo, Toledo, OH), 6-cyano-7nitroquinoxaline-2,3-dione (CNQX; RBI, Natick, MA), D(-)-2-amino5-phosphonopentanoic acid (AP5), ZD 7288 (ZD; Tocris, Ellisville, $\mathrm{MO}$ ), bicuculline, $\mathrm{CsCl}$, picrotoxin and tetrodotoxin, and mibefradil (Sigma). GABA (Sigma) was dissolved in normal medium at $0.5 \mathrm{~mm}$ and was locally delivered through a micropipette ( $1-2 \mu \mathrm{m}$ in diameter) positioned at 50-100 $\mu \mathrm{m}$ from the tested cell and connected to a pneumatic ejection system (Picospritzer; Intracel, Shepreth, Royston, Hertfordshire, UK).

Identification of recorded neurons. At the end of the recording, neurons were filled with biocytin (1\%) using hyperpolarizing current pulses. This was not necessary for patch clamp recording. Slices were then fixed in $4 \%$ paraformaldehyde and $0.15 \%$ picric acid for $2 \mathrm{~h}$ at room temperature and rinsed in $4 \%$ paraformaldehyde $(2 \times 20 \mathrm{~min})$. Biocytin was visualized with streptavidin-conjugated Texas Red fluorescence (Biosys, Compiègne, France) with appropriate filters (Leitz DMR microscope; Leica, Rueil-Malmaison, France). Slices then underwent double immunofluorescence for OT or vasopressin, using a mixture of primary antibodies, one being a monoclonal mouse Ig raised against OT-related neurophysin (OT-NP; provided by Dr. H. Gainer, National Institutes of Health, Bethesda, MD), the other a polyclonal rabbit serum raised against vasopressin-associated neurophysin (VP-Np; provided by Dr. A. Robinson, University of California, Los Angeles, Los Angeles, CA).

\section{Results}

All of the results reported in this study have been obtained in 153 OT magnocellular neurons, which were identified according to two criteria: (1) their ability to display high-frequency bursts of action potentials which are a specific property of OT neurons (Jourdain et al., 1998; Israel et al., 2003), and (2) post hoc immunoidentification. Intracellular recordings $(n=122)$ obtained from these neurons revealed a mean resting membrane potential of $-54.6 \pm 5.0 \mathrm{mV}(n=50)$, a mean input resistance of $237.0 \pm$ $40.9 \mathrm{M} \Omega(n=50)$, and action potentials (APs) of $71.9 \pm 10.9 \mathrm{mV}$ ( $n=250$ from 50 cells).

\section{OT upregulates GABAergic transmission}

Intracellular recordings in current-clamp mode in the presence of TTX $(1 \mu \mathrm{M})$, bicuculline $(15 \mu \mathrm{M})$, CNQX $(10 \mu \mathrm{M})$, and APV $(40 \mu \mathrm{M})$ indicated that bath-applications of OT $(10-1000 \mathrm{nM})$ did not affect the resting membrane potential nor the input resistance of OT neurons (Fig. 1A1-A3). Bath-application of OT $(100 \mathrm{nM})$ in normal medium did not alter the amplitude $(98.4 \pm$ $5.2 \%$ of control; $n=8, p>0.05)$ or frequency $(95.4 \pm 3.6 \%$ of control, $n=8, p>0.05$ ) of EPSPs recorded at $-80 \mathrm{mV}$ (data not shown). Under conditions where EPSPs were blocked with CNQX $(10 \mu \mathrm{M})$ and AP5 $(40 \mu \mathrm{M})$, low concentrations (25 to 100 nM) of OT significantly and reversibly increased IPSPs (Fig. $1 B$ ) and IPSCs (Fig. $2 A$ ) in 56 of 78 neurons (72\%). In the remaining neurons $(28 \%)$, OT did not affect GABAergic activity (Fig. $1 B$ ) and these cells were thus considered as nonresponsive to the neurohypophysial peptide. In OT-responsive cells, the enhanced IPSP activity was associated with an increase in the frequency $(257 \pm 41 \%$ of control; $p<0.05 ; n=7)$ and amplitude $(211 \pm$ $52 \%$ of control; $p<0.05 ; n=7$ ) of spontaneous events (Fig. $2 \mathrm{~B}, \mathrm{C})$. OT-sensitive IPSPs/IPSCs were blocked by bicuculline $(15 \mu \mathrm{M})$, showing that synaptic events modulated by OT were mediated by $\mathrm{GABA}_{\mathrm{A}}$ receptors (data not shown). The effect of OT was mimicked by a specific OT-R agonist, [4-7] OT (100 nM; $n=$ 6) which increased the frequency (377 $\pm 82 \%$ of control; $p<$ $0.05)$ and amplitude $(283 \pm 78 \%$ of control; $p<0.05)$ of spontaneous IPSPs (Fig. 2C). Conversely, the effect of $50 \mathrm{~nm}$ OT was blocked in the presence of $1 \mu \mathrm{M}$ D-OVT, a specific OT-R antagonist $(79 \pm 31 \%$ and $91 \pm 9 \%$ of control in frequency and amplitude, respectively; $n=4$ ) (Fig. $2 C$ ).

To identify the locus of action of OT, TTX ( $1 \mu \mathrm{M})$ was added to the external solution to block AP-driven inhibitory synaptic events and thus make sure that monoquantal synaptic responses (miniatures) were recorded. For these experiments we used the whole-cell patch-clamp technique in voltageclamp configuration instead of intracellular sharp electrode recording. Under these conditions, OT (50 nM) significantly increased the frequency $(198.3 \pm 29.3 \%$ of control, $n=4 ; p<$ $0.05)$ but not the amplitude (103.5 $\pm 8.1 \%$ of control, $n=4$; $p>0.05$ ) of miniature IPSCs (Fig. $2 D-F$ ). Although this set of 
data implies that OT-R are located presynaptically on GABAergic neuron terminals impinging on OT cells, they do not rule out the possibility that OT-R are also located on GABA neuron somata or on other neurons contacting GABAergic cells, and that these receptors also contribute to facilitate inhibitory activity in OT neurons.

\section{Bimodal dose-dependent action of OT on inhibitory transmission}

The stimulatory effect of OT on GABAergic transmission was dose-dependent, with a threshold of $25 \mathrm{~nm}$ and a maximal facilitation at $50 \mathrm{~nm}$ (Fig. 3A). Higher concentrations of OT progressively inhibited GABAergic synaptic activity. The inhibition was almost total with $300 \mathrm{~nm}$ OT, a result in agreement with the postsynaptic inhibitory action of OT on $\mathrm{GABA}_{\mathrm{A}}$ receptors previously reported in the SON (Brussaard et al., 1996). The dynamics and dose-dependency of these two opposite effects of OT on GABAergic transmission were then compared by monitoring simultaneously synaptic currents and responses obtained with local puffs of GABA. Whereas low concentrations of OT ( $50 \mathrm{~nm}$ ) triggered IPSP activity without affecting the amplitude of GABA-induced responses, IPSP amplitude and frequency gradually decreased when increasing OT concentrations, with a complete inhibition obtained at 1000 nM (Fig. $3 B, D$ ). In the same recordings, GABA-induced responses were slightly affected when OT concentration reached $500 \mathrm{nM}$ and were completely inhibited with $2000 \mathrm{~nm}$ (Fig. 3C,D). These findings demonstrate that OT acts both at presynaptic and postsynaptic levels, depending on its concentration, to upregulate or downregulate GABAergic transmission.

\section{OT-mediated IPSPs facilitate firing}

In intracellular current-clamp recordings, low concentrations of OT (50-100 nM) increased the firing activity in 11 of 27 OT neurons (183 $\pm 17 \%$ of control) (Fig. $4 A 1, A 2)$. To identify the cellular mechanism responsible for this increase in firing rate, and its possible relation to OTmediated facilitation of inhibitory transmission, we investigated the action of OT on OT neuron electrical activity in the presence of CNQX to block EPSPs (Fig. $4 B$ ). Whereas CNQX inhibited AP firing, as reported previously (Jourdain et al., 1996), OT still triggered spiking activity at resting membrane potential in 15 of 36 neurons $(41 \%)$. Examination of recordings at high resolution revealed that during such OT-triggered activity, most APs occurred at the end of the repolarizing phase of individual IPSPs (Fig. 4B3,B4). This was particularly clear during OT washout where IPSP fre-

\section{B3}

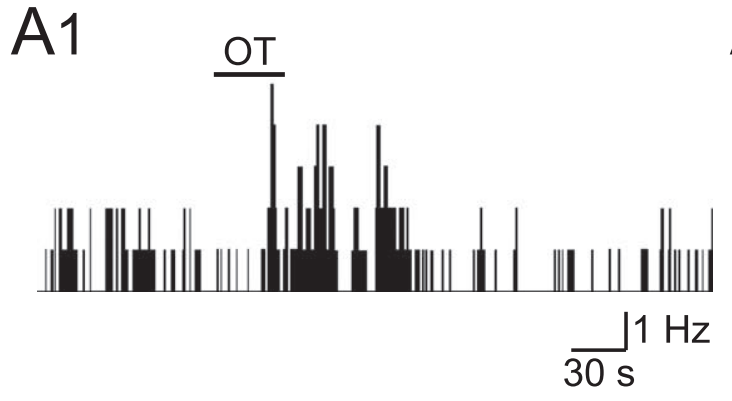

A2
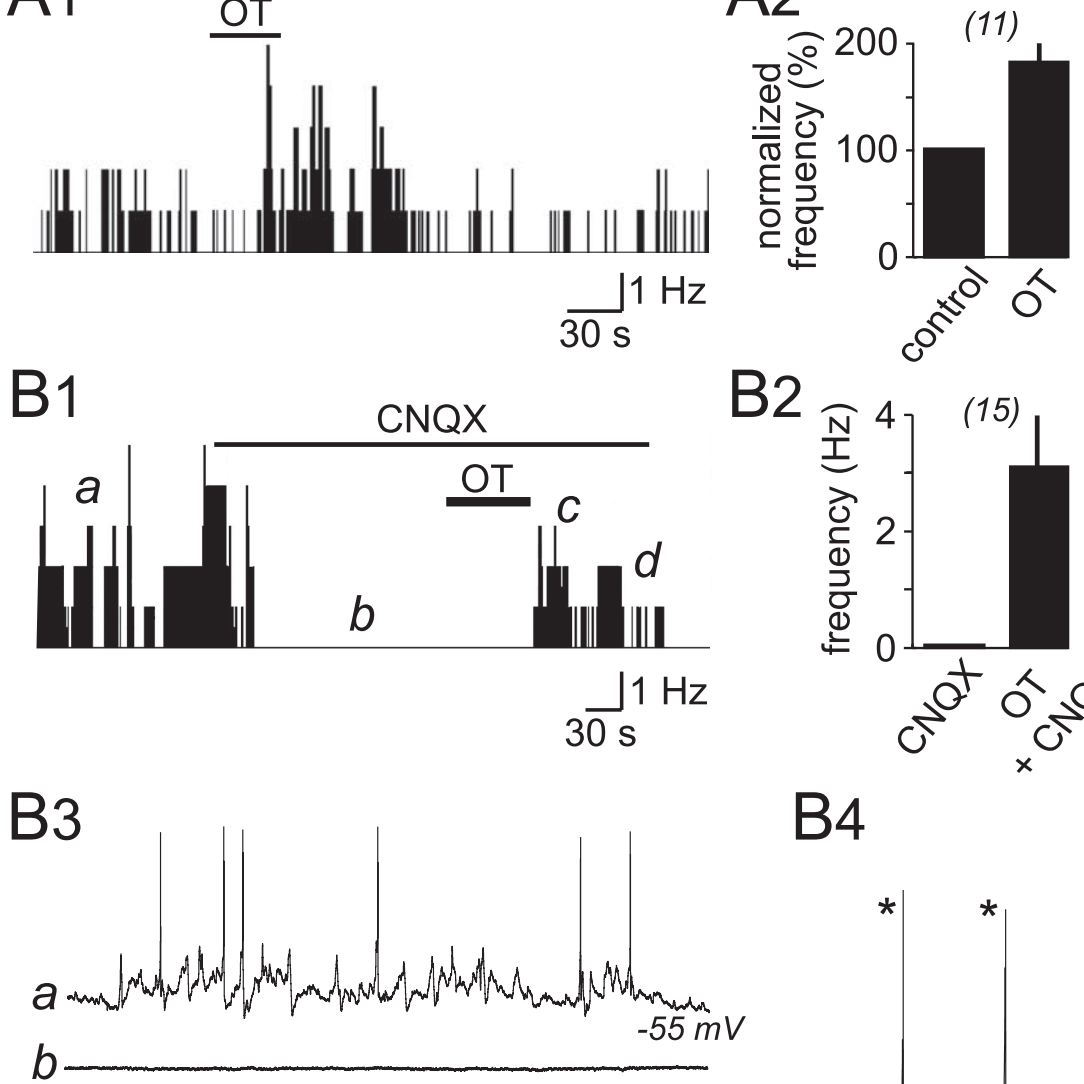

B4
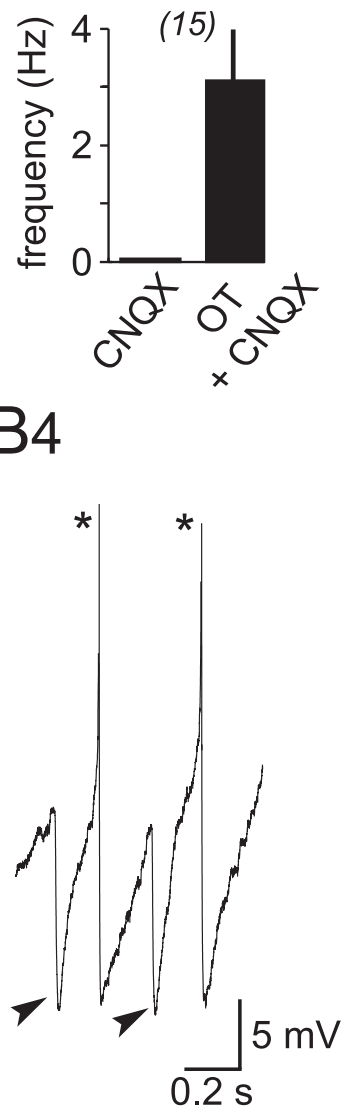

Figure 4. OT-induced IPSP activity triggers AP firing. A1, Example of an OT neuron where exogenous application of OT ( $50 \mathrm{~nm}$ ) increased firing activity in a reversible manner as illustrated by the change in the sequential frequency histogram. $\mathbf{A} 2$, Histogram summarizing the stimulatory effect of $0 \mathrm{~T}$ on firing rate. The number of cells is indicated in brackets. $\boldsymbol{B}$, Under conditions where CNQX totally abolished spontaneous firing (b), OT (50 nM) still triggered AP discharge (c). B2, Summary histogram showing the stimulatory effect of OT in the presence of CNQX. B3, Traces obtained from the recording shown in B1. In control conditions (a), APs were mainly triggered by EPSPs. CNQX totally abolished EPSP activity and APs firing (b). Subsequent addition of OT (50 nM) dramatically increased IPSP activity (arrow heads) and restored AP firing (c). During washout of OT, although IPSP frequency and AP firing decreased, spikes were still occurring at the end of IPSPS (d). B4, Magnification of the trace c shown in B3 revealed that APs (asterisks) occurred at the offset of IPSPs (arrowheads).

quency decreased to values $<5 \mathrm{~Hz}$, making it easier to reveal the link between IPSP and AP firing (Fig. 4B3, trace d). That APs were exclusively governed by IPSPs was confirmed in a series of experiments where this OT-triggered firing occurring in the presence of CNQX was completely inhibited by the specific $\mathrm{GABA}_{\mathrm{A}}$ receptor antagonist picrotoxin $(5 \mu \mathrm{M})$ (Fig. $5 A)(n=5)$. It is worth noting that we never observed an increased in AP firing without an increase in IPSP activity. 
A in cnox
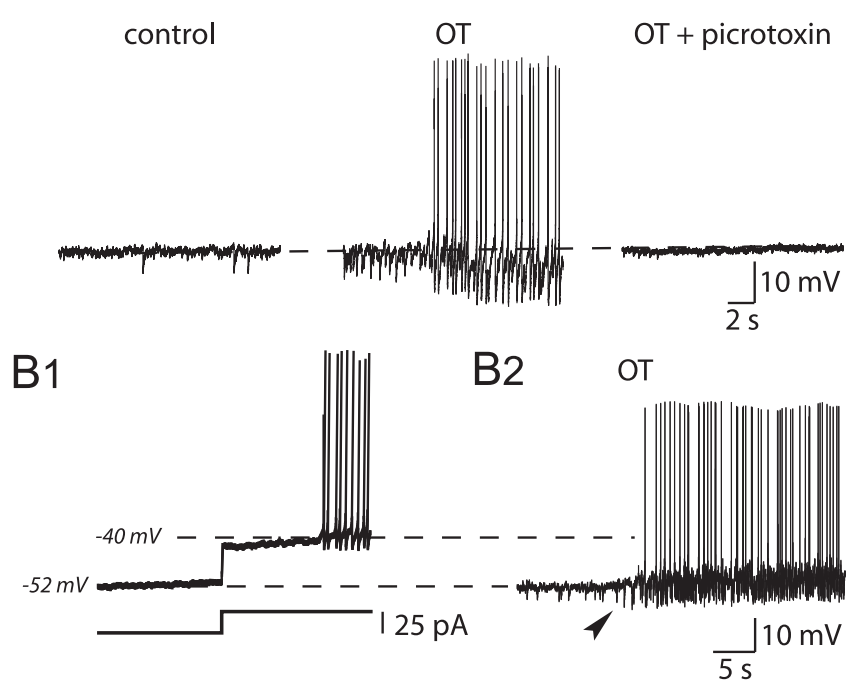

Figure 5. OT-triggered APs are exclusively governed by IPSPs. $A$, In the presence of CNQX, OT (50 nM) dramatically increased IPSP activity and firing (middle), an action that was totally blocked by picrotoxin ( $5 \mu \mathrm{m}$; right). $\boldsymbol{B}$, In the presence of $C \mathrm{NQX}$ and $\mathrm{AP5}$, a positive step current was required to depolarize the cell and trigger firing. B2, OT (50 nм) under the same conditions and in the same neuron triggered IPSPs (arrowhead) and AP firing without depolarizing the membrane.

nied by a consistent increase in IPSP activity preceding the appearance of APs. These findings suggest that OT, by triggering or dramatically increasing the occurrence of IPSPs, paradoxically facilitates firing activity in OT neurons. These results prompted us to investigate the cellular mechanism underlying this phenomenon.

\section{Ionic mechanisms underlying OT-induced firing}

In presence of CNQX, each OT-triggered spike occurred at the end of the repolarizing phase of an individual IPSP (Fig. 4B4). Such process is reminiscent of PIR, as described in other structures (Bertrand and Cazalets, 1998; Angstadt et al., 2005; Sohal et al., 2006). PIR is defined as the depolarization that occurs at the offset of a hyperpolarizing period. At least, two nonexclusive mechanisms might account for PIR-induced spikes. One involves LVA Ca ${ }^{2+}$ channels that are first deinactivated by hyperpolarization and then activated during the repolarization period (Bertrand and Cazalets, 1998, Jahnsen and Llinas, 1984; Fan et al., 2000), thereby generating a depolarization known as a lowthreshold spike (LTS). This LTS, if of a sufficient amplitude, can generate APs (Huguenard, 1996). A second possibility is the activation of a hyperpolarization-activated inward current $\left(I_{\mathrm{H}}\right)$ which underlies rebound responses in many neurons (Matsushima et al., 1993; Straub and Benjamin, 2001; Sekirnjak and du Lac, 2002).

Both LVA $\mathrm{Ca}^{2+}$ current and $I_{\mathrm{H}}$ have been described in SON and PVN neurons
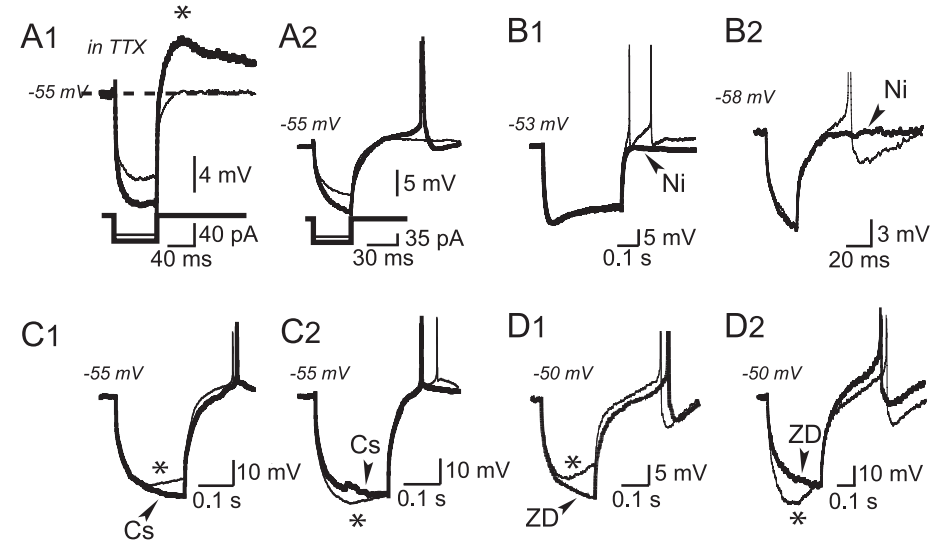

Figure 6. Presence of a low-threshold spike (LTS) in OT neurons. A1, In the presence of TTX, a negative current ( $50 \mathrm{~ms},-40$ pA, thick traces) injected in an OT neuron at $-55 \mathrm{mV}$, triggered an LTS (asterisk) at the offset of the current step. This LTS was abolished when the amplitude of the pulse was decreased ( $-30 \mathrm{pA}$, thin traces). A2, When negative current steps ( -50 and $-70 \mathrm{pA}, 40 \mathrm{~ms}$ ) were applied from $-55 \mathrm{mV}$, only the larger current step triggered a rebound spike (thick trace). $\boldsymbol{B}, \mathrm{APs}$ (thin traces) triggered by long ( $350 \mathrm{~ms} ; \boldsymbol{B}$ 1) and brief $(25 \mathrm{~ms} ; \boldsymbol{B} 2)$ hyperpolarized pulses were inhibited (thick traces) by $100 \mu \mathrm{m} \mathrm{Ni}{ }^{2+}$ (Ni). Forty micromolar mibefradil (Mib) also inhibited such pulses-triggered APs (B3). C1, A depolarizing sag (asterisk) typical of $I_{H}$ activation was observed during voltage responses to negative current injections (thin traces). This sag was blocked with $\mathrm{Cs}^{+}$ (Cs, 3 mм; thick trace) whereas pulse-triggered APs remained unaffected. $\mathbf{C 2}, \ln \mathrm{Cs}^{+}$, adjusting the hyperpolarization to the control value to compensate for the change in membrane resistance associated with $/_{H}$ blockade did not affect pulse-triggered AP firing. D1, Inhibition of $I_{H}$ with the specific antagonist ZD 7288 (ZD; $50 \mu \mathrm{m}$, thick trace), did not affect $200 \mathrm{~ms}$ long pulse-triggered APs. D2, As for Cs ${ }^{+}$, pulse-triggered AP firing was not affected when the hyperpolarization was adjusted to the control value in the presence of ZD. D3, APs triggered by brief ( $25 \mathrm{~ms}$ ) hyperpolarizing pulses were not affected by ZD.

The interaction between OT-mediated IPSP activity and the facilitation of firing activity was confirmed in another set of experiments in which APs were triggered in response to membrane depolarization in the presence of ionotropic glutamate receptors inhibitors (CNQX and AP5). As illustrated in Figure 5B1, OT neurons started to fire APs only once the membrane potential reached spike threshold $(-38.1 \pm 4.3 \mathrm{mV}, n=7)$. In the same recordings, OT triggered spike discharge without depolarizing the membrane potential (Fig. 5B2), an effect that was accompa-
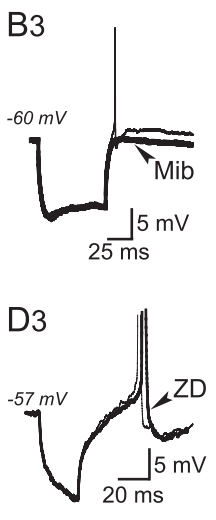

(Fisher and Bourque, 1995; GhamariLangroudi and Bourque, 2000; Luther and Tasker, 2000). Thus, we first checked for their presence in our cultured slices before studying their respective contribution to OT-mediated PIR-firing. Because the presence of LVA Ca ${ }^{2+}$ channels is associated with the generation of an LTS, we applied brief $(50 \mathrm{~ms})$ hyperpolarizing pulses in the presence of TTX to block $\mathrm{Na}^{+}$-dependent APs. As illustrated in Figure 6A1, such pulses triggered a rebound depolarization typical of an LTS in 17 of 32 neurons, a process that was compromised when the amplitude of the negative step was reduced, as previously described (Erickson et al., 1993). In the absence of TTX, such hyperpolarizing pulses triggered rebound APs (Fig. 6A2). To study the contribution of LVA $\mathrm{Ca}^{2+}$ channels to this process, we bath-applied $\mathrm{Ni}^{2+}$ at $100 \mu \mathrm{M}$, a concentration that inhibits $\mathrm{T}$-type $\mathrm{Ca}^{2+}$ currents (Fisher and Bourque, 1995) and blocks LTS (Erickson et al., 1993) in SON neurons. In agreement with a role for these channels in LTS generation, APs triggered by long $(>100 \mathrm{~ms} ; n=5)$ (Figs. 6 B1, 7B1) or brief (25 ms; $n=6$ ) (Figs. 6B2, 7B2) hyperpolarizing pulses were completely abolished in the presence of this inhibitor. Because $\mathrm{Ni}^{2+}$ might also interact with other voltage-gated $\mathrm{Ca}^{2+}$ channels, we tested the action of mibefradil, a compound considered to be a specific T-type channel antagonist (Van der Vring et al., 1999). At a concentration of $40 \mu \mathrm{M}$, mibefradil also inhibited pulsetriggered APs $(n=5)$ (Fig. 6B3, 7B1). Together, these data suggest that the LVA Ca ${ }^{2+}$ channels mediating LTS in these neurons are of the T-type. 
We then examined the role of $I_{\mathrm{H}}$ in this process. During $100 \mathrm{~ms}$ long hyperpolarizing pulses, we reliably observed the typical depolarizing sag in the voltage response (Fig. 6C1,D1) that reflects activation of $I_{\mathrm{H}}$ (Ghamari-Langroudi and Bourque, 2000). As previously reported (GhamariLangroudi and Bourque, 2001), this sag was inhibited by $3 \mathrm{~mm}$ external $\mathrm{Cs}^{+}(n=$ 4) (Fig. $6 C 1)$ or by $50 \mu \mathrm{M} \mathrm{ZD}(n=5)$ (Fig. $6 D 1$ ), two well known blockers of $I_{\mathrm{H}}$. Conversely, this sag was not affected in the presence of $\mathrm{Ni}^{2+}$ or mibefradil (Fig. $6 B 1, B 3)$. Interestingly, blockade of $I_{\mathrm{H}}$ with Cs or ZD did not prevent pulse-triggered rebound spikes (Figs. $6 C 1, D 1,7 B 1$ ) even when hyperpolarization was adjusted to that obtained in control conditions to compensate for changes in membrane resistance (Fig. 6C2,D2). The lack of effect of $\mathrm{ZD}$ on pulse-triggered APs was also observed with pulses of shorter duration (25 $\mathrm{ms} ; n=6$ ) (Figs. 6D3, 7B2).

$\mathrm{Ni}^{2+}$, mibefradil, $\mathrm{Cs}^{+}$, and $\mathrm{ZD}$ were then used to assess the respective contribution of LVA Ca ${ }^{2+}$ channels and $I_{\mathrm{H}}$ to OTmediated PIR firing. As illustrated in Figure $7 A$ and summarized in $C, \mathrm{Ni}^{2+}(n=4)$ and mibefradil $(n=5)$ inhibited AP firing, but not IPSP activity (Fig. 7D), triggered by OT. However, neither $\mathrm{Cs}^{+}(n=4)$ nor ZD $(n=4)$ affected significantly OT-triggered firing activity (Fig. $7 A, C$ ) or IPSPs (Fig. $7 D)$. These data suggest that IPSPs can trigger rebound firing through the recruitment of LVA $\mathrm{Ca}^{2+}$ channels. If this is true, a rebound depolarization should be observed after individual IPSPs. In four cells where OT-triggered AP firing and IPSP activity were not intense enough to mask such a phenomenon, rebound excitations were clearly observed after inhibitory synaptic potentials (Fig. 8A1,A2; see also Fig. $4 B 3$, trace d). These rebounds were not affected by the subsequent application of $\mathrm{ZD}$ (Fig. $8 B 1, B 2$ ) whereas they were completely abolished in the presence of $\mathrm{Ni}^{2+}$ (Fig. 8C1,C2). As illustrated on the averaged traces in Figure $8 D$ and from cumulative histograms in Figure $8 E$, inhibition of the rebound depolarization with $\mathrm{Ni}^{2+}$ resulted in an increased IPSP width, an effect that was not observed with ZD. We thus used IPSP duration to assess the effect of the different blockers on IPSP-triggered postinhibitory rebound excitation. Whereas both $\mathrm{Ni}^{2+}$ and mibefredil increased IPSP duration (126 $\pm 12 \%$ of control, $n=4$ for $\mathrm{Ni}^{2+} ; 121 \pm 9 \%, n=4$, for mibefradil), neither ZD nor $\mathrm{Cs}^{+}$modified significantly this parameter (Fig. $8 \mathrm{~F}$ ). Together, these findings reveal the involvement of LVA Ca ${ }^{2+}$ channels, but not of $I_{\mathrm{H}}$, in IPSP-mediated postinhibitory rebound firing. These data also indicate that IPSPs have to be of sufficient amplitude to trigger AP firing, which may not be the case under control conditions.

\section{Physiological relevance}

Throughout this study, OT neurons recorded in the absence of glutamatergic and GABAergic blockers usually displayed a bursting activity, either spontaneously or in response to bath application of 100 nм OT (Fig. 9A) (Jourdain et al., 1998, Israel et al.,
$\mathrm{B}_{1}$

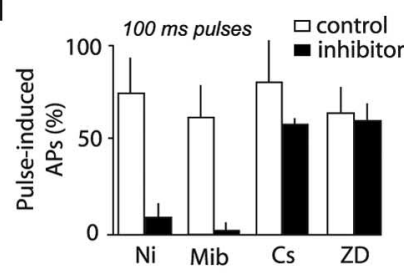

$\mathrm{B} 2$

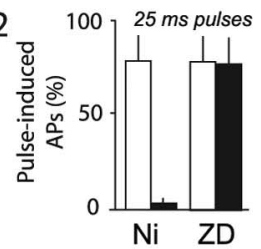

C

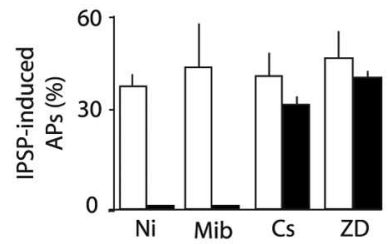

D

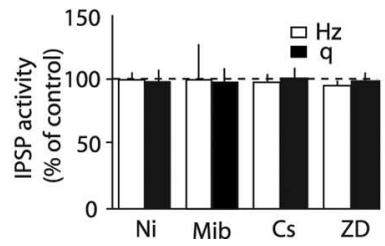

OT $\quad$ OT + ZD
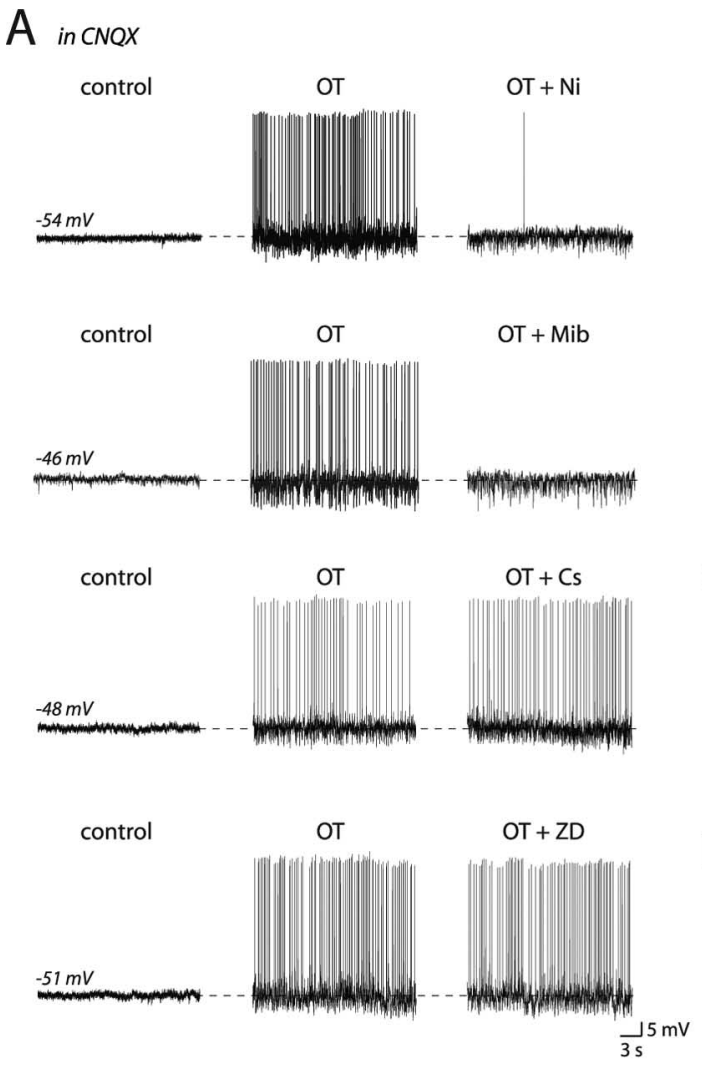

OT

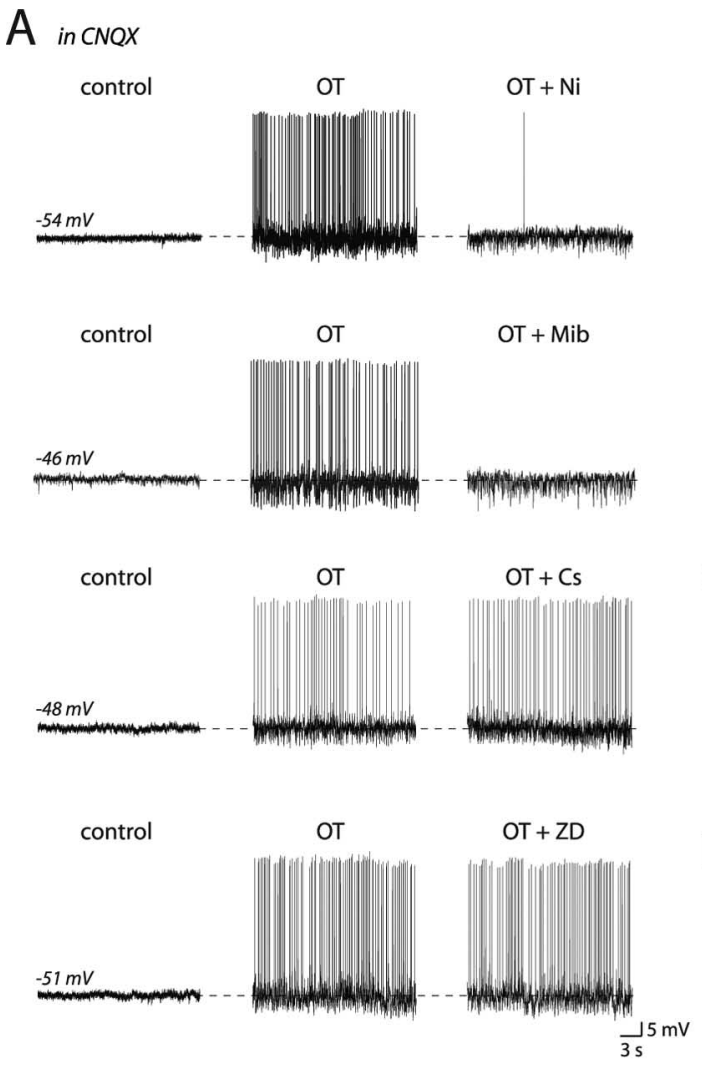

OT + Mib

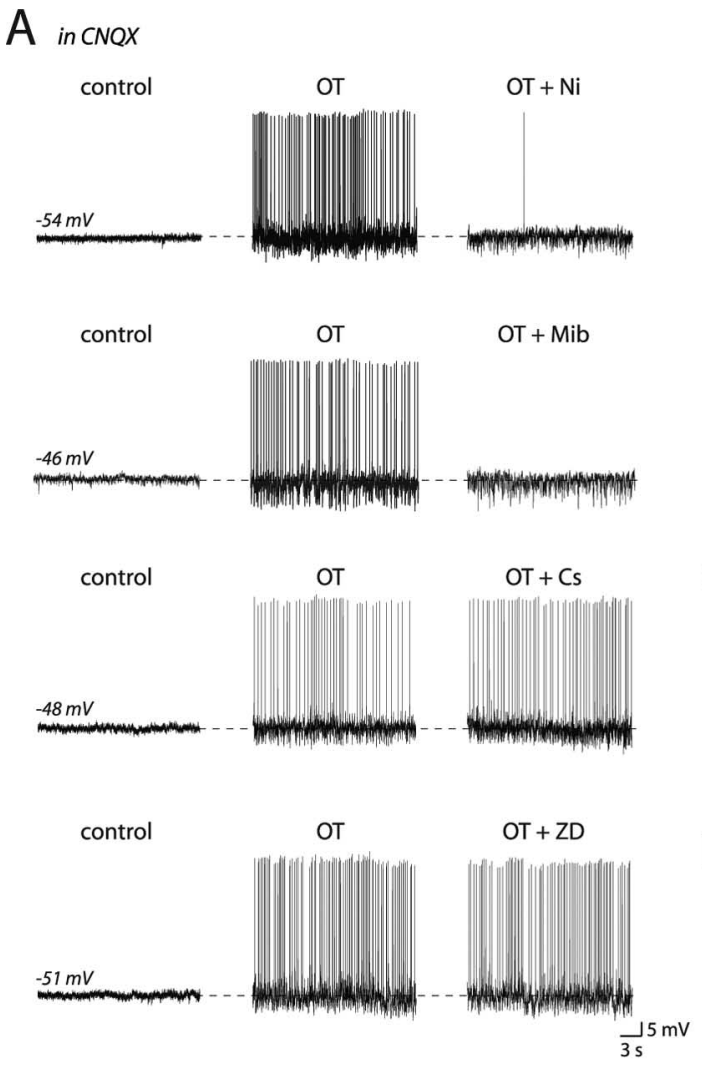

\section{c}

Figure 7. OT-mediated postinhibitory rebound firing is blocked by low-threshold-activated calcium current blockers. $A$, In CNQX-containing medium (control; left panel), firing activity triggered by $50 \mathrm{nм}$ OT (middle panel) was strongly inhibited by 100 summarizing the action of $\mathrm{Ni}^{2+}$ and ZD 7288 on APs triggered by long $(>100 \mathrm{~ms} ; \boldsymbol{B}$ 1) and brief $(25 \mathrm{~ms} ; \boldsymbol{B 2})$ hyperpolarizing pulses. $C$, Histograms summarizing the action of $\mathrm{Ni}^{2+}$, mibefradil, $\mathrm{Cs}^{+}$and ZD 7288 on $\mathrm{OT}$-induced PIR firing. $\boldsymbol{D}, \mathrm{Ni}^{2+}$, mibefradil, $\mathrm{CS}^{+}$and ZD 7288 did not affect the frequency $(\mathrm{Hz})$ nor the amplitude $(\mathrm{q})$ of $0 \mathrm{~T}$-triggered IPSPs.

2003). This activity is characteristic of that recorded in vivo in lactating rats (Lincoln and Wakerley, 1975). Careful analysis of this activity in cultured slices revealed an increase in firing rate occurring just before burst onset in $40 \%$ of the neurons (Fig. $9 A$ ). Such increases in background firing rate immediately preceding the bursts have been already reported in vivo where they are directly and positively correlated to the magnitude of the bursting activity itself (Lincoln and Wakerley, 1975). This prompted us to investigate whether a similar type of correlation prevailed in OT neurons recorded from organotypic slice cultures, and to test whether OT-mediated PIR firing was playing a role in this process.

Within bursts, both the mean AP frequency and the peak frequency (over $0.5 \mathrm{~s}$ ) were increased ( $175 \pm 38 \%$ of control and $183 \pm 40 \%$ of control, respectively; $n=25)$ in neurons showing an enhanced background firing activity before burst onset (Fig. $9 B 1, B 2)$. To further analyze burst magnitude, we used the same index as described by Lincoln and Wakerley which corresponds to the number of spikes within the burst multiplied by the peak frequency (Lincoln and Wakerley, 1975). As illustrated in Figure $9 C$, the burst index was positively correlated $(r=0.61 ; n=48$ bursts from 15 cells) to the firing frequency measured $20 \mathrm{~s}$ before the incidence of each burst, a result in complete agreement with previous in vivo data (Lincoln and Wakerley, 1975; Brown et al., 2000).

Although the bursts are driven by glutamatergic inputs (Jourdain et al., 1998; Israel et al., 2003), the origin of the increase in background firing rate in OT cells is unknown. One possibility is 


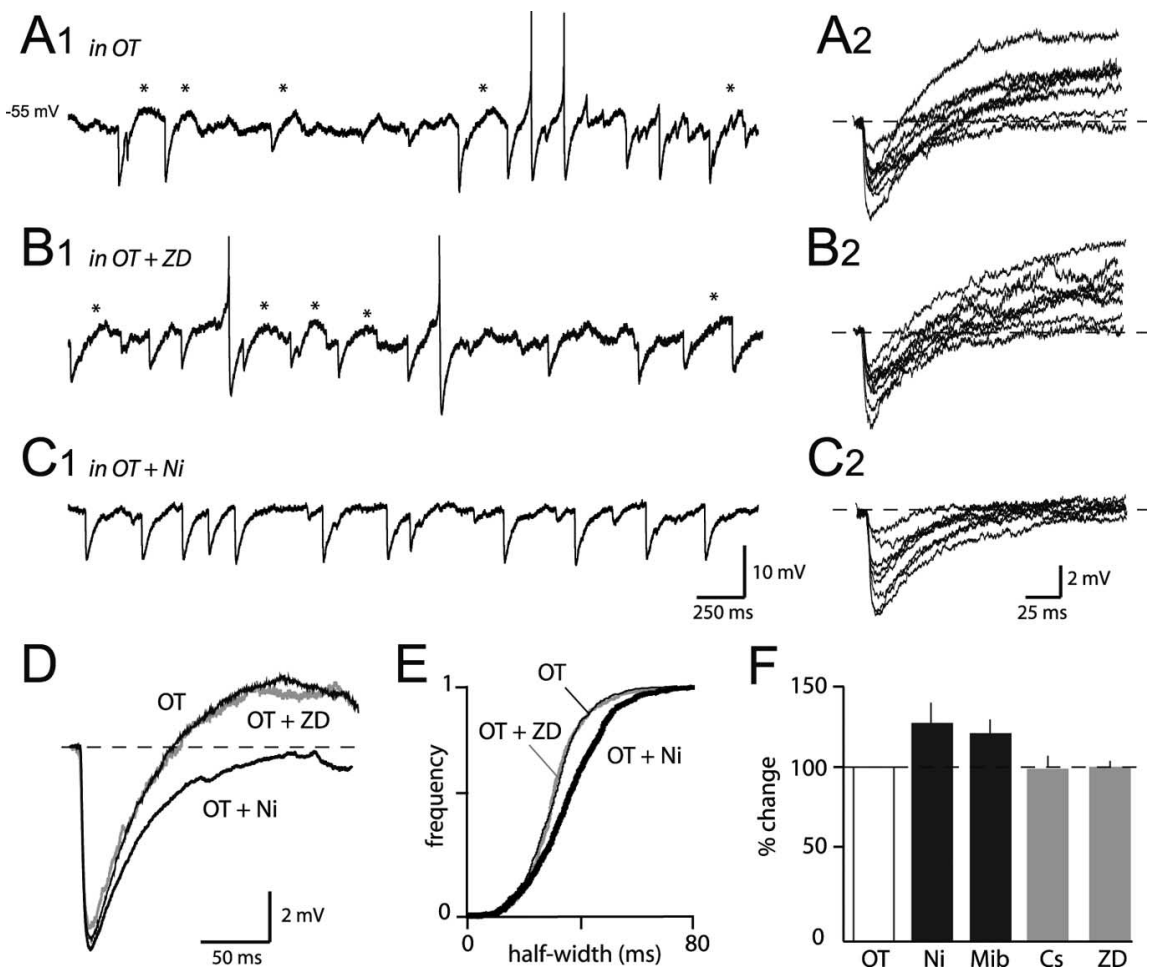

Figure 8. IPSP-mediated rebound depolarization. A1, Example of a recording obtained in the presence of CNQX and $50 \mathrm{~nm}$ OT showing the presence of rebound depolarizations (asterisks) occurring at the end of IPSPs. A2, Superimposition of eight consecutive IPSPs obtained from the recording in $\boldsymbol{A} \boldsymbol{1}$ clearly shows that a rebound depolarization follows several of these inhibitory potentials. B1, B2, In the same recording, application of ZD did not affect the occurrence of such IPSP-triggered rebound depolarizations. C1, C2, Subsequent addition of $100 \mu \mathrm{M} \mathrm{Ni}{ }^{2+}$ in the bathing solution completely abolished AP firing and rebound depolarizations. D, Average IPSPs ( $n=93-105)$ obtained from the recordings shown in $\boldsymbol{A}-\boldsymbol{C}$. This graph shows that rebound depolarization was unaffected by ZD (gray trace) whereas it was abolished in the presence of $\mathrm{Ni}^{2+}$. Note that IPSP duration was increased with $\mathrm{Ni}^{2+}$. $E$, Cumulative histograms representing the distribution of IPSP half-width obtained from the recording shown in $\boldsymbol{A}-\boldsymbol{C}$. This distribution was significantly shifted toward higher values in the presence of $\mathrm{Ni}^{2+}$. $\boldsymbol{F}$, Summary histogram illustrating the percentage change in the half-width of 0 T-triggered IPSPs ( $n=4$ cells). Whereas IPSP duration was significantly increased by $\mathrm{Ni}^{2+}$ and mibefradil (Mib), it remained unchanged in the presence of $\mathrm{Cs}^{+}$or $\mathrm{ZD}$.

that this phenomenon is attributable to OT-mediated PIR firing. To test this hypothesis, we analyzed synaptic activity just before the occurrence of each burst. EPSP activity occurring during this period remained unchanged whether an increase in background firing rate occurred or not (Fig. 10A). On the contrary, in neurons that displayed an increase in firing rate before the bursts, a marked increase in both amplitude ( $155 \pm 12 \%$ of control; $n=$ $10 ; p<0.05)$ and frequency $(189 \pm 39 \%$ of control; $n=10 ; p<$ 0.05 ) of IPSPs occurred (Fig. 10A,B). These findings strongly support a relationship between IPSP activity and increased background firing rate. Because IPSP-mediated PIR firing is related to $\mathrm{OT}$, it is likely that the increased firing observed in these neurons resulted from the dendritic release of endogenous OT. If this is true, then activation or inhibition of OT-R should affect background firing and, consequently, the burst index. In agreement with this hypothesis, OT (50-100 nM) increased the mean firing rate before burst onset from $2.3 \pm 0.7 \mathrm{~Hz}$ to $4.78 \pm 1.24 \mathrm{~Hz}$ $(211 \pm 41 \%$ of control, $n=5)$ (Figs. 9C, $10 C 1, D)$ whereas the OT-R antagonist D-OVT decreased it from $2.98 \pm 0.20 \mathrm{~Hz}$ to $0.98 \pm 0.40(32 \pm 14 \%$ of control, $n=4)$ (Figs. $9 C, 10 C 2, D)$. In these neurons, OT and D-OVT respectively augmented (163 \pm $26 \%, n=5$ ) and diminished (36 $\pm 19 \%$ of control) the burst index as expected (Fig. 10D). It is noteworthy that in the presence of OT, a concomitant increase in IPSP frequency (190 $\pm 26 \%$ of control, $n=5, p<0.05)$ and amplitude (191 $\pm 35 \%$ of control, $n=5, p<0.05)$ occurred (Fig. 10E), whereas D-OVT by itself, induced an opposite effect (frequency, $73 \pm 6 \%$ of control, $n=4, p<0.05$; amplitude, $56 \pm 9 \%$ of control, $n=4, p<0.05$ ) (Fig. 10E). This suggests that endogenous ambient OT has a positive action on IPSP activity and, consequently, on burst magnitude.

\section{Discussion}

Action potential firing in neurons is usually obtained when the membrane potential is depolarized above spike threshold. This generally occurs through activation of ion channels or ligand-gated receptors or through the relief of tonic inhibition, a process known as disinhibition. Another mechanism promoting neuronal firing, although less usual, is PIR. In this phenomenon, one to several APs can be generated during the membrane repolarization that follows the offset of a hyperpolarizing event. PIR may involve $I_{\mathrm{H}}$, deinactivation of voltage-gated $\mathrm{Ca}^{2+}$ currents or both. Such process is responsible for triggering activity in motoneurons (Bertrand and Cazalets, 1998) in thalamocortical neurons (Sohal et al., 2006) and in rat caudal hypothalamic neurons (Fan et al., 2000) for example. Here, we described a process in which a peptide, oxytocin, by facilitating the occurrence of hyperpolarizing GABAergic synaptic potentials, promotes AP discharge through PIR firing. This process potentiates bursting activity of OT neurons which is responsible for the massive and intermittent release of OT in the blood, and thus for pup delivery and milk ejection.

\section{OT modulation of firing activity in OT neurons}

The low concentrations of OT that we used here $(25-100 \mathrm{nM})$ is more compatible with physiological concentration, as suggested by microdialysis experiments (Neumann et al., 1993). Interestingly, the facilitatory action of OT on IPSP activity was observed in $72 \%$ of OT neurons. That such low concentrations of OT accelerate firing in OT-responsive neurons through the generation of IPSPs is paradoxical because hyperpolarizing synaptic potentials are usually associated with inhibition rather than facilitation of firing activity. The action of OT was receptor-mediated because it was mimicked by an OT-R agonist and inhibited by an OT-R antagonist. Similar upregulation of GABAergic activity has been reported in CA1 hippocampal neurons (Zaninetti and Raggenbass, 2000) and in putative vasopressin hypothalamic neurons (Hermes et al., 2000) in response to OT and VP, respectively. Furthermore, our experiments revealed that OT-mediated GABAergic activation facilitated AP firing in $\sim 40 \%$ of OT neurons. Although moderate, this increase in firing rate was in the range of that reported in lactating rat in vivo in response to local OT applications (Brown et al., 2000).

How can a GABAergic inhibitory synapse become excitatory? Several mechanisms may underlie IPSP-mediated PIR firing. One involves an LTS resulting from deinactivation of LVA $\mathrm{Ca}^{2+}$ currents, as described previously in the SON (Fisher and 
A

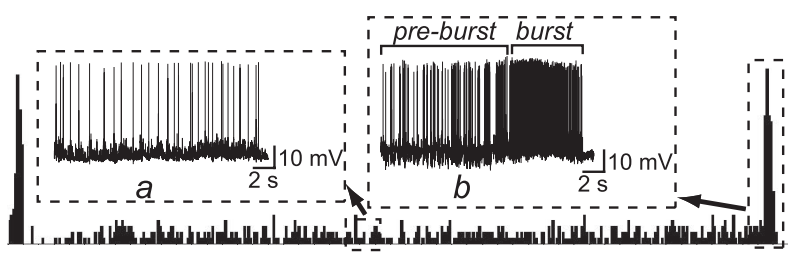

B1
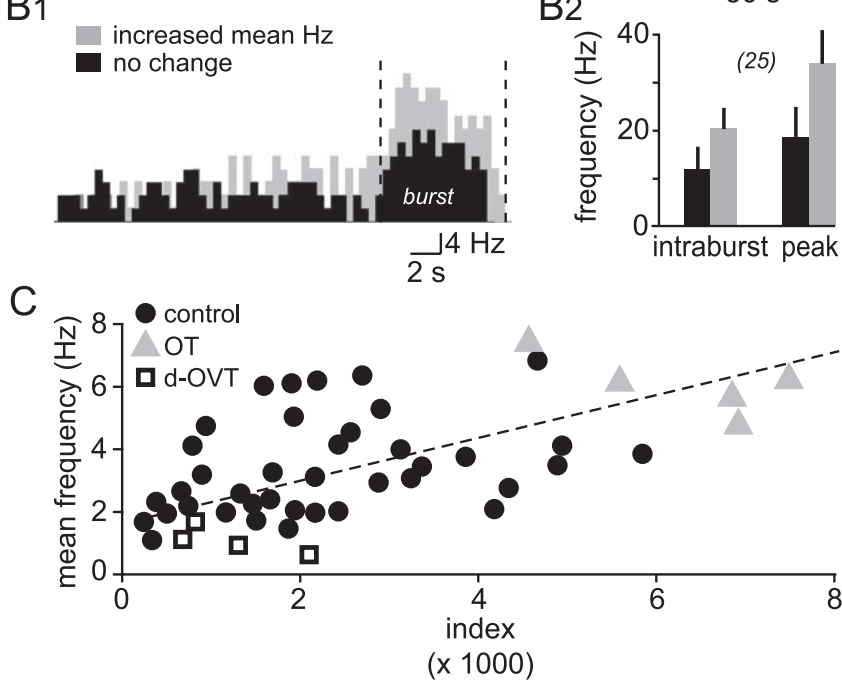

Figure 9. Preburst firing and burst magnitude in $0 \mathrm{~T}$ neurons. $A$, Frequency histogram $(\mathrm{FH})$ illustrating the bursting activity of an $0 \mathrm{~T}$ neuron recorded in cultured slices. Insets show the raw recording at the time indicated before and during a burst. B1, Superimposition of FHs recorded from two $0 \mathrm{~T}$ neurons displaying (gray) or not (black) an increased firing activity before the occurrence of a burst. Burst magnitude was larger in the neuron showing such an increase. $\mathbf{B 2}$, Summary histogram illustrating the mean intraburst frequency and the mean peak frequency in neurons showing (gray; $n=25$ ) or not showing (black; $n=25$ ) an increased firing rate before burst occurrence. C, Correlation between burst magnitude (index) and firing rate before the burst (mean frequency). Data were obtained from control experiments (black dots; $n=39$ ), with $50-100$ nм 0T (gray triangles; $n=5$ ) and 100 nм D-OVT (empty squares; $n=4$ ). The dotted line represents the linear regression through the data points obtained under control conditions $(r=0.61)$.

Bourque, 1995, Erickson et al., 1993, Dudek et al., 1989). This is likely to be the case here for several reasons. First, the percentage of neurons exhibiting an LTS is similar to that displaying OTtriggered firing. Second, rebound OT-triggered depolarizations and spikes were entirely blocked by $\mathrm{Ni}^{2+}$ at concentrations known to inhibit LTS and LVA Ca ${ }^{2+}$ current in these cells (Erickson et al., 1993; Fisher and Bourque, 1995) and by mibefradil, a more specific T-type channel antagonist (Van der Vring et al., 1999). Although these data suggest that T-type channels are responsible for mediating IPSP-induced PIR firing in OT neurons, the definitive demonstration for the implication of these channels awaits new and more specific pharmacological tools. Similarly, it remains to be determined which $\mathrm{Ca}_{\mathrm{V}} \mathrm{T}$ subunits among those already detected in hypothalamic neurons (Craig et al., 1999; Talley et al., 1999) are implicated in this process. In SON neurons, activation of $I_{\mathrm{H}}$ could also account for PIR firing (Ghamari-Langroudi and Bourque, 2000): this can be ruled out because $\mathrm{Cs}^{+}$and ZD 7288 inhibited $I_{\mathrm{H}}$ without affecting OTmediated firing.

\section{Heterogeneity of OT actions}

It is clear from our observations that OT mediates distinct effects in the SON according to its concentration. At $50 \mathrm{~nm}$, OT stimulated the frequency and amplitude of IPSPs/IPSCs, suggesting
A
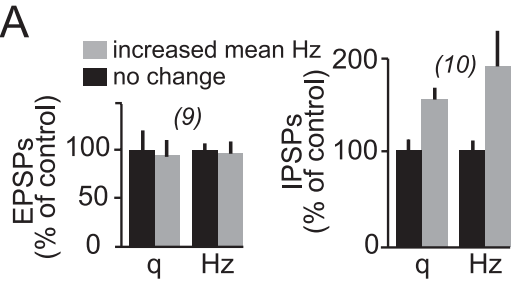

B

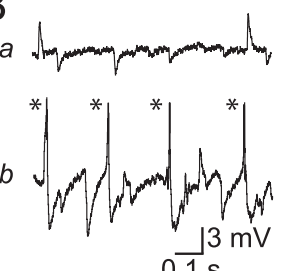

C1
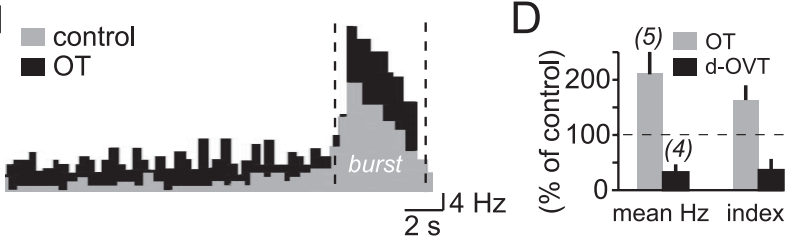

$\mathrm{C} 2$
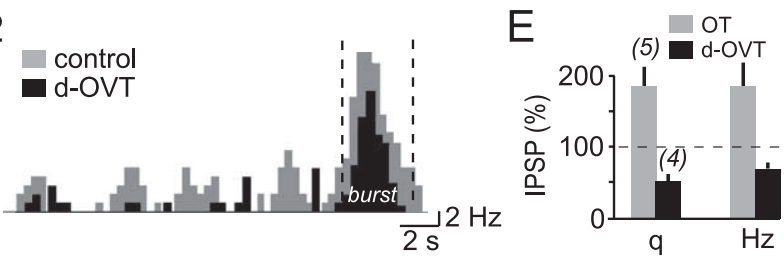

Figure 10. Contribution of OT-mediated rebound firing to OT neuron bursting activity. $\boldsymbol{A}_{\text {, }}$ Histograms summarizing the percentage change in the amplitude (q) and frequency $(\mathrm{Hz})$ of EPSPs (left) and IPSPs (right) in OT neurons showing (gray bars) or not showing (black bars) an increased firing rate before burst occurrence. $\boldsymbol{B}$, Sample traces extracted from the recording shown in Figure $9 A$ at the time indicated. Detailed analysis revealed a dramatic increase in IPSP activity and AP (asterisks) firing before burst occurrence (b). C1, Superimposition of FHs before (gray) and after (black) application of $100 \mathrm{~nm}$ OT. Note that OT induced a marked increase in background activity and burst magnitude. (2, FHs before (gray) and after (black) application of $100 \mathrm{~nm}$ D-OVT. Note that the antagonist D-OVT decreased both background activity and burst magnitude. $\boldsymbol{D}$, Histograms summarizing the changes in background firing (mean $\mathrm{Hz}$ ) and in burst magnitude (index) caused by OT (gray) and D-OVT (black). The numbers of experiments are indicated in brackets. $\boldsymbol{E}$, Under $0 \mathrm{~T}$ treatment (gray bars), IPSPs occurring before the burst showed a marked increase in their amplitude $(\mathrm{q})$ and frequency $(\mathrm{Hz})$, whereas D-OVT (black bars) inhibited both parameters.

that it can act both presynaptically and postsynaptically. In the presence of TTX, the frequency but not the amplitude of mIPSCs was increased, whereas postsynaptic responses to applications of GABA were unaffected, indicating a presynaptic site of action of OT. At concentrations $>50 \mathrm{~nm}$, OT progressively inhibited both the frequency and amplitude of IPSPs with a complete blockade obtained at $1000 \mathrm{nM}$, a result in agreement with the inhibitory action of OT on GABA release previously described (De Kock et al., 2003) and which has been related to the release of endocannabinoids acting on presynaptic CB1 receptors (Oliet et al., 2007). At such high concentrations, OT also inhibited $\mathrm{GABA}_{\mathrm{A}}$ receptor mediated postsynaptic responses (Brussaard et al., 1996). Together, our results reveal, therefore, that depending on its concentration, OT has presynaptic effects, increasing then decreasing the probability of GABA release, and postsynaptic effects, inhibiting $\mathrm{GABA}_{\mathrm{A}}$ receptors on OT neurons.

It is obvious from this and our previous studies (Jourdain et al., 1998; Israel et al., 2003) that OT acts differently, according to its concentration and its targets, namely, GABA, glutamate and OT neurons. Such heterogeneity of actions may reflect differences in OT-R mediating these responses. However, although there is evidence supporting the existence of different receptor subtypes, only one type of OT-R has been described so far (Gimpl and Fahrenholz, 2001). Alternatively, if there is only one type of OT-R, there may be a differential expression of this receptor in different cells and/or different OT-R-coupled second messenger pathways (Verbalis, 1999). 


\section{Physiological considerations}

At parturition and during suckling, local release of OT from the somatodendritic compartment is necessary to trigger and facilitate the periodic activation of OT neurons (Freund-Mercier and Richard, 1984; Moos et al., 1984). We have shown previously that OT neuron bursting is controlled by an intrahypothalamic network in which bursting glutamate neurons govern OT neurons. In turn, OT somatodendritic release is essential to modulate the bursting pattern of glutamatergic neurons (Jourdain et al., 1998; Israel et al., 2003). The modulation of GABA transmission by OT as reported here may provide another mean of generating APs during background activity, in addition to those generated by EPSPs. Such a process may also explain previous in vivo data obtained in lactating rats showing that locally applied GABA unexpectedly facilitated bursting activity (Moos, 1995) whereas the same activity was impaired when $\mathrm{GABA}_{\mathrm{A}}$ receptors were inhibited (Voisin et al., 1995).

We here showed a strong correlation between background firing activity before each burst and the magnitude of the bursts, a result similar to that reported in vivo (Lincoln and Wakerley, 1975; Brown and Moos, 1997). One likely explanation to account for this observation is that such an increase in firing rate facilitates the somatodendritic release of OT, thereby increasing its ambient concentration and range of action in the extracellular space. This, in turn, could positively modulate the intrahypothalamic pacemaker neurons responsible for the bursting activity of OTsecreting cells (Jourdain et al., 1998). In agreement with this hypothesis, we noticed that activation of OT-R with exogenous OT increased background firing rate and, consequently burst magnitude, as reported in vivo (Brown et al., 2000) whereas inhibiting OT-R with D-OVT had the opposite effect. In view of these data, it appears that OT-mediated PIR firing is an important process by which OT neurons could not only regulate their own activity but also influence the efficacy of the intrahypothalamic network generating the bursting behavior responsible for pup delivery and milk ejection. These results are reminiscent of those obtained in vivo where OT neurons showing an increase in their background firing rate before the bursts have been described as "leader" neurons whose task is to recruit "follower" neurons to optimize the activation of the entire OT network, thereby maximizing synchronized bursting activity (Moos et al., 2004).

\section{References}

Angstadt JD, Grassmann JL, Theriault KM, Levasseur SM (2005) Mechanisms of postinhibitory rebound and its modulation by serotonin in excitatory swim motor neurons of the medicinal leech. J Comp Physiol 191:715-732.

Bertrand S, Cazalets JR (1998) Postinhibitory rebound during locomotorlike activity in neonatal rat motoneurons in vitro. J Neurophysiol 79:342-351.

Brown D, Moos F (1997) Onset of bursting in oxytocin cells in suckled rats. J Physiol (Lond) 503:625-634.

Brown D, Fontanaud P, Moos FC (2000) The variability of basal action potential firing is positively correlated with bursting in hypothalamic oxytocin neurones. J Neuroendocrinol 12:506-520.

Brussaard AB, Kits KS, De Vlieger TA (1996) Postsynaptic mechanism of depression of GABAergic synapses by oxytocin in the supraoptic nucleus of immature rat. J Physiol (Lond) 497:495-507.

Craig PJ, Beattie RE, Folly EA, Banerjee MD, Reeves MB, Priestley JV, Carney SL, Sher E, Perez-Reyes E, Volsen SG (1999) Distribution of the voltagedependent calcium channel alphalG subunit mRNA and protein throughout the mature rat brain. Eur J Neurosci 11:2949-2964.

De Kock CP, Wierda KDB, Bosman LWJ, Min R, Koksma JJ, Mansvelder HD, Verhage M, Brussaard AB (2003) Somatodendritic secretion in oxytocin neurons is upregulated during the female reproductive cycle. J Neurosci 23:2726-2734.
Dudek FE, Tasker J, Wuarin JP (1989) Intrinsic and synaptic mechanisms of hypothalamic neurons studied with slice and explant preparations. J Neurosci Methods 28:59-69.

Erickson KR, Ronnekliev OK, Kelly MJ (1993) Role of a T-type calcium current in supporting a depolarizing potential, damped oscillations, and phasic firing in vasopressinergic guinea pig supraoptic neurons. Neuroendocrinology 57:789-800.

Fan YP, Horn EM, Waldrop TG (2000) Biophysical characterization of rat caudal hypothalamic neurons: calcium channel contribution to excitability. J Neurophysiol 84:2896-2903.

Fisher TE, Bourque CW (1995) Voltage-gated calcium currents in the magnocellular neurosecretory cells of the rat supraoptic nucleus. J Physiol (Lond) 486:571-580.

Freund-Mercier M, Richard P (1984) Electrophysiological evidence for facilitatory control of oxytocin neurones by oxytocin during suckling in the rat. J Physiol (Lond) 352:447-466.

Ghamari-Langroudi M, Bourque CW (2000) Excitatory role of the hyperpolarization-activated inward current in phasic and tonic firing of rat supraoptic neurons. J Neurosci 20:4855-4863.

Ghamari-Langroudi M, Bourque CW (2001) Ionic basis of the caesiuminduced depolarisation in rat supraoptic nucleus neurones. J Physiol (Lond) 536:797-808.

Gimpl G, Fahrenholz F (2001) The oxytocin receptor system: structure, function, and regulation. Physiol Rev 81:629-683.

Gouzènes L, Desarménien MG, Hussy N, Richard P, Moos FC (1998) Vasopressin regularizes the phasic firing pattern of rat hypothalamic magnocellular vasopressin neurons. J Neurosci 18:1879-1885.

Hermes MLHJ, Ruijter JM, Klop A, Buijs RM, Renaud LP (2000) Vasopressin increases GABAergic inhibition of rat hypothalamic paraventricular nucleus neurons in vitro. J Neurophysiol 83:705-711.

Huguenard JR (1996) Low-threshold calcium currents in central nervous system neurons. Annu Rev Physiol 58:329-348.

Israel JM, Le Masson G, Theodosis DT, Poulain DA (2003) Glutamate afferent input governs periodicity and synchronization of bursting electrical activity in oxytocin neurons in hypothalamic organotypic cultures. Eur J Neurosci 17:2619-2629.

Jahnsen H, Llinas R (1984) Ionic basis for the electroresponsiveness and oscillatory properties of guinea-pig thalamic neurones in vitro. J Physiol (Lond) 349:227-247.

Jourdain P, Poulain DA, Theodosis DT, Israel JM (1996) Electrical properties of oxytocin neurons in organotypic cultures from postnatal rat hypothalamus. J Neurophysiol 76:2772-2785.

Jourdain P, Israel JM, Dupouy B, Oliet SHR, Allard M, Vitiello S, Theodosis DT, Poulain DA (1998) Evidence for a hypothalamic oxytocin-sensitive pattern-generating network governing oxytocin neurons in vitro. J Neurosci 18:6641-6649.

Kombian SB, Mouginot D, Pittman QJ (1997) Dendritically-released peptides act as retrograde modulators of afferent excitation in the supraoptic nucleus in vitro. Neuron 19:903-912.

Lambert RC, Moos FC, Richard PH (1993) Action of endogenous oxytocin within the paraventricular or supraoptic nuclei: a powerful link in the regulation of the bursting pattern of oxytocin neurons during the milkejection reflex in rats. Neuroscience 57:1027-1038.

Lincoln DW, Wakerley JB (1975) Factors governing the periodic activation of supraoptic and paraventricular neurosecretory cells during suckling in the rat. J Physiol (Lond) 250:443-461.

Ludwig M, Leng G (2006) Dendritic peptide release and peptide-dependent behaviours. Nat Rev Neurosci 7:126-136.

Luther JA, Tasker JG (2000) Voltage-gated currents distinguish parvocellular from magnocellular neurones in the rat hypothalamic paraventricular nucleus. J Physiol (Lond) 523:193-209.

Matsushima T, Tegnér J, Hill RH, Grillner S (1993) GABAB receptor activation causes a depression of low- and high-voltage-activated $\mathrm{Ca}^{2+}$ currents, postinhibitory rebound, and postspike afterhyperpolarization in lamprey neurons. J Neurophysiol 70:2606-2619.

Moos F, Freund-Mercier MJ, Guerne Y, Guerne JM, Stoeckel ME, Richard P (1984) Release of oxytocin and vasopressin by magnocellular nuclei in vitro: specific facilitatory effect of oxytocin on its own release. J Endocrinol 102:63-72.

Moos F, Poulain DA, Rodriguez F, Guerne Y, Vincent JD, Richard P (1989) Release of oxytocin within the supraoptic nucleus during the milk ejection reflex in rats. Exp Brain Res 76:593-602. 
Moos F, Fontanaud P, Mekaouche M, Brown D (2004) Oxytocin neurones are recruited into co-ordinated fluctuations of firing before bursting in the rat. Neuroscience 125:391-410.

Moos FC (1995) GABA-induced facilitation of the periodic bursting activity of oxytocin neurones in suckled rats. J Physiol (Lond) 488:103-114.

Neumann ID, Russell JA, Landgraf R (1993) Oxytocin and vasopressin release within the supraoptic and paraventricular nuclei of pregnant, parturient and lactating rats: a microdialysis study. Neuroscience 53:65-75.

Oliet SH, Baimoukhametova DV, Piet R, Bains JS (2007) Retrograde regulation of GABA transmission by the tonic release of oxytocin and endocannabinoids governs postsynaptic firing. J Neurosci 27:1325-1333.

Poulain DA, Wakerley JB (1982) Electrophysiology of hypothalamic magnocellular neurones secreting oxytocin and vasopressin. Neuroscience 7:773-808.

Richard P, Moos F, Freund-Mercier MJ (1991) Central effects of oxytocin. Physiol Rev 71:331-370.

Sekirnjak C, du Lac S (2002) Intrinsic firing dynamics of vestibular nucleus neurons. J Neurosci 22:2083-2095.

Sohal VS, Pangratz-Fuehrer S, Rudolph U, Huguenard JR (2006) Intrinsic and synaptic dynamics interact to generate emergent patterns of rhythmic bursting in thalamocortical neurons. J Neurosci 26:4247-4255.
Straub VA, Benjamin PR (2001) Extrinsic modulation and motor pattern generation in a feeding network: a cellular study. J Neurosci 21:1767-1778.

Talley EM, Cribbs LL, Lee JH, Daud A, Perez-Reyes E, Bayliss DA (1999) Differential distribution of three members of a gene family encoding low voltage-activated (T-type) calcium channels. J Neurosci 19:1895-1911.

Van der Vring JA, Cleophas TJ, Van der Wall EE, Niemeyer MG (1999) T-channel-selective calcium channel blockade: a promising therapeutic possibility, only preliminarily tested so far: a review of published data. T-channel Calcium Channel Blocker Study Group. Am J Ther 6:229-233.

Verbalis JG (1999) The brain oxytocin receptor(s?). Front Neuroendocrin 20:146-156.

Voisin DL, Herbison AE, Poulain DA (1995) Central inhibitory effects of muscimol and bicuculline on the milk ejection reflex in the anaesthetized rat. J Physiol (Lond) 483:211-224.

Wakerley JB, Clarke G, Summerlee AJS (1988) Milk ejection and its control. In: The physiology of reproduction. (Knobil E, Neill J, eds), pp 11311177. New York: Raven.

Zaninetti M, Raggenbass M (2000) Oxytocin receptor agonists enhance inhibitory synaptic transmission in the rat hippocampus by activating interneurons in stratum pyramidale. Eur J Neurosci 12:3975-3984. 